\title{
Implementation of SCOR Based Business Process Framework for Logistics and Supply Chain in Retail Company
}

\author{
Andrejs Girjatovičs ${ }^{1}$, Laila Māra Rizoto-Vidala-Pesoa ${ }^{2}$, Oksana Kuzṇecova ${ }^{3}$ \\ ${ }^{1,3}$ RIMI Baltic, Riga, Latvia, \\ ${ }^{2}$ Cabot Corporation, Riga, Latvia
}

\begin{abstract}
The paper describes the implementation of process management methodology SCOR in a retail company. The supply chain operations reference model (SCOR) provides process management methodology, including processes, their metrics, benchmarking and diagnostic tools to assist an organisation in enhancing supply chain processes. The model contains multiple sections and is composed of management processes, such as Plan, Source, Make, Deliver, Return and Enable. The model can be used to describe processes of supply chains that are simple or very complex using a common set of definitions. As a result, processes of companies from different industries can be measured against industry peers using the same metrics. The paper summarises important milestones and lessons learnt during implementation of SCOR in a retail company. It explains benefits of SCOR, as well as main challenges in the implementation of new process modelling framework.
\end{abstract}

Keywords - APQC, business process, GSCF, SCM frameworks, SCOR model, supply chain management.

\section{INTRODUCTION}

Supply chain management is an integrating function with primary responsibility for linking major business functions and business processes within and across companies into a cohesive and high-performing business model [1]. Important part of SCM is coordination and collaboration with partners, such as suppliers, third-party service providers, and customers; providers and partners are called under one name of supply chain management (SCM), which normally includes all management, planning activities involved in sourcing, procurement and all logistics management activities. Managing effectively this complex system of interconnected activities, which are usually geographically spread, requires first of all the understanding of the existing processes from the perspective of their execution, input, output and related procedures. Therefore, the necessity of the process description framework is evident for any company where logistics and supply chain processes are under the focus of effective management. The necessity of the business process descriptions is also vital when it comes to process automation, unification, harmonization, optimization or any other development initiatives, as all of them require a clear understanding of the existing processes and their interconnections. Finally, digitalization and business transformation are only then possible to be done in an effective way, when there is a clear understanding of the existing processes within a company.
Over past decades, business process modelling as well as business process framework has grown up to an abnormal variety of tools and methodologies. Numerous discussions are still ongoing about the definition of process-related terminology, such as process, activity, procedures and instructions. The complexity is coming when applying clear in readings concepts to the practical exercises of inventing process framework in companies. The more complex the processes of the company are, the more complicated any project of process description is.

The paper presents a case study of the implementation of business process framework for logistics and supply chain process description. The necessity of inventing a standardised business process framework in a retail company was raised by a strategic project of harmonization of logistics and supply chain processes. A pre-study of the existing process descriptions showed few very critical shortcomings. They were mainly related to a typical misconception of process as a description of what employees are doing instead of focusing on value added activities to delivering a product or service through the entire supply chain. At the beginning of the paper, different frameworks are presented, which were initially considered for process description. Then, the framework implementation phase is described to show the main milestones of implementation.

\section{CHOOSING SCM FRAMEWORK}

Since the mid-1990s, academics in the fields of logistics, marketing, and operations management have attempted to describe supply chain processes [2]. Frameworks are used to have same language for communicating ideas, concepts, and methodologies, as well as discussing and documenting supply chain activities. In some cases, they also create a process framework linked to performance measurement (metrics) that can communicate the relevance of the supply chain management strategy to everyone in the organisation. Without such a framework, it is difficult to capture the strategic implications of SCM because decision makers cannot align or measure the effectiveness of actions and decisions relative to a corporate strategy [1]. The existing frameworks have different scope and focus. Most commonly used frameworks in the supply chain industry are listed below. 


\section{A. SCOR Model}

SCOR was developed in 1996 by the management consulting firm PRTM, now part of PricewaterhouseCoopers LLP (PwC) and AMR Research, now part of Gartner, and endorsed by the Supply-Chain Council (SCC), now part of APICS [3], as the cross-industry de facto standard strategy, performance management, and process improvement diagnostic tool for supply chain management.

The SCOR model describes the business activities associated with satisfying a customer's demand, including Plan, Source, Make, Deliver, Return and Enable processes. Use of the model includes analysing the current state of a company's processes, as well as quantifying operational performance by using a set of standard metrics.

The description of supply chain SCOR model is available in public resources of the Internet; however, differences in model description or visualization might come with a version of SCOR. Currently version 12.0 is available under affiliation of APICS membership. The main difference of version 12.0 of the process framework comparing with previous versions is coming with establishing the Enable process as a separate component in the entire supply chain process map (Fig.1). [4]
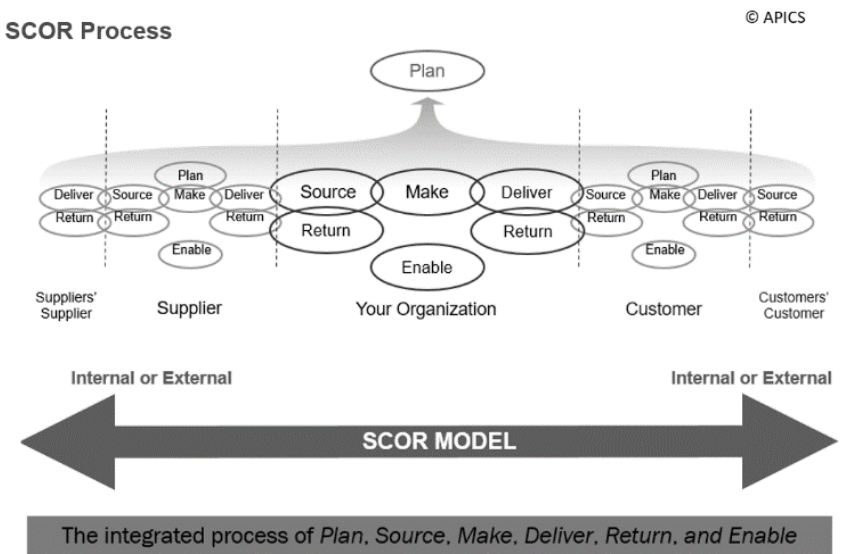

Fig. 1. SCOR model organisation.

In recent 10 years, the interest in SCOR as a methodological sourcing of supply chain process, metrics, benchmark and capabilities has grown up. Many journals have reported on significant improvements after companies have adopted the SCOR model. Research [5] based on 125 North American manufacturing companies showed the empirical evidence that the SCOR model was in fact valid.

The idea and transparency is attractive as there are papers exploring applicability of the SCOR for identifying key performance indicators for a third-party logistics service provider [6]. A strong benefit of SCOR is its strong hierarchy on supply chain performance metrics, which allows users to diagnose performance problems and identify action for improvement on the process level. The performance attributes of SCOR model (reliability, responsiveness, flexibility, cost measures and asset management efficiency) are used as the basis for defining the KPIs.

\section{B. GSCF Framework}

The GSCF framework was developed by executives from a group of multi-national companies later called the Global Supply Chain Forum (GSCF) [2].

The Global Supply Chain Forum includes noncompeting companies and a team of academic researchers who have been meeting regularly since 1992 with the objective of improving the theory and practice of SCM [1].

The main components of the GSCF framework are [2] management components that support process planning and control, work structure, organisational structure, product flow facility structure, information flow, management methods, power and leadership structure, risk and reward structure, as well as culture and attitude.

The concept of GSCF [7] includes the following SCM processes: customer relationship management, customer service management, demand management, order fulfilment, manufacturing flow management, supplier relationship management, product development and commercialization, returns management.

Framework concept is based on full integration and management of these processes. Since all the eight processes are cross-functional, and full integration is critical, each functional unit in the supply chain must be involved in the implementation of those processes [1].

The role of framework is to provide a highly integrated and collaborative process within an organisation, which allows achieving better demand planning, reduced inventory levels, improved productivity and reduced costs [7]. To get a benefit from usage of this framework, organisation processes must be highly connected and very well managed.

\section{APQC Framework}

APQC (American Productivity \& Quality Center) is a member-based non-profit organisation around the world in all sectors of business, education, and government. It was founded in 1977 to help organisations improve productivity and quality by providing best practice research, metrics, and measures. In 2014, APQC worked to enhance the cross-industry and updated several industry-specific process classification frameworks [8].

There are 12 cross-organisational operating and management process categories as shown in Fig. 2. They are decomposed into process groups, processes, activities and tasks.

Many of framework elements have a description and could be used to develop standard definitions used across an organisation.

Similarly to SCOR, APQC has suggested metrics that can be used to develop process KPIs. Likewise SCOR, APQC offers benchmarking data.

In the context of the full organisation, like in the SCOR framework, processes and activities are organised into levels:

- $\quad 1^{\text {st }}$ level represents the "process category" level. This is the highest PCF level;

- $2^{\text {nd }}$ level represents the "process group" level within each process category;

- $3^{\text {rd }}$ level represents the "process" level within each process group; 


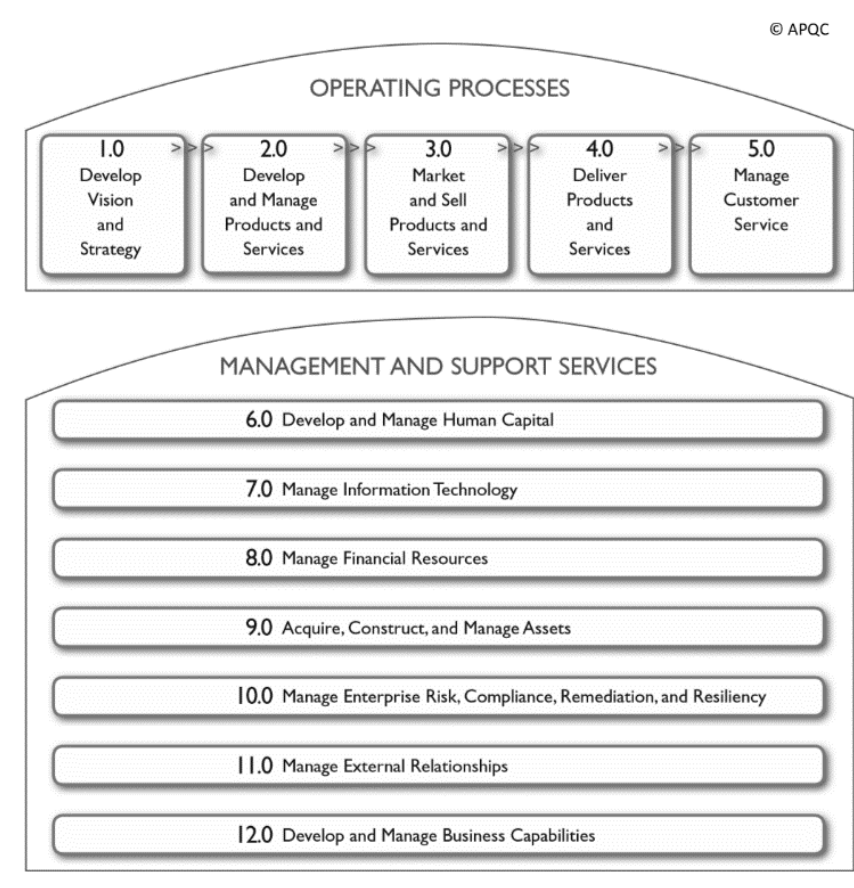

Fig. 2. The AFQC framework organisation.

- $4^{\text {th }}$ level represents the "activities" level within each process;

- $5^{\text {th }}$ level represents the "task" level as the next level of hierarchical decomposition.

Despite the SCOR, which is fully dedicated to supply chain processes, APQC has the following supply chain related process categories: 4.0 (Deliver product and services) and 5.0 (Manage customer service). Together they include supply chain planning, procurement, manufacturing, logistics, and customer order management [13].

APQC framework is designed as a standard applicable to all industries with provided industry specific versions. Taking it into account, new companies can implement framework and use it as the starting point to formulate their supply chain processes.

APQC provides industry, geography, and company size neutral benchmarking data. This information can be used by these peer groups for relevant comparison of their performance with industry leaders [1].

The model is suggested to organisations that realise the importance of strategic partnerships as well as collaboration within functions [1].

\section{Selection of the Framework}

The process of selection of the methodology was executed through the research studies and communication to framework owners. From the business perspective, the following requirements were identified as a must and discussed among other expectations that business process framework should deliver to the company:

- Strong and strict process descriptions; preferably based on industry standards. This is important to avoid miscommunication and misunderstanding of process content, including input and output.
- Performance metrics and calculations details. This is necessary for (1) understanding of every process improvement value proposition and (2) enhancement of existing KPI scorecard.

- Benchmarking as a tool for considering process improvement opportunities during harmonization journey.

- Methodological support during implementation of the framework.

After the several rounds of discussion with framework providers, the decision was made to choose the SCOR framework. Apart from the main criteria for the selection, strong attention of APICS to digitalization and Omni channel are prospective in a long-term plan of the company.

Other frameworks mentioned above have their strong sides and can be used as the basis of process description framework for retail companies. However, due to several reasons they were not fully applicable to the company needs at the current moment of time. First, GSCF framework does not provide strong benchmarking service. Second, to use this framework company processes must be highly integrated and well-managed at the entire level of the company performance.

Both APQC framework and SCOR provide a great benchmarking possibility; however, APQC relies mostly on the performance metrics submitted by companies, while SCOR has a dedicated service executed by a well-known leader of the research and consultancy. The metrics of the APQC framework are mostly related to process efficiency, while SCOR focuses on business performance metrics, which are the priority for the company.

SCOR [9] model has been chosen among other frameworks to be used for establishing a supply chain end-to-end process framework within a company. The decision rationale is driven by the following main reasons:

- SCOR has a dedicated focus on supply chain processes;

- SCOR is an industry standardised supply chain description framework;

- SCOR is a process-focused framework;

- SCOR supports continuous improvement by providing a benchmarking service;

- SCOR provides a detailed analysis of best practices, including emergency practices, best practices and standard practices, which can be applied for company needs,

- SCOR allows for the development of training and education programmes to further supply chain knowledge;

- SCOR ensures methodological support provided by APICS, the leading provider of supply chain, logistics and operations management research, publications, and education and certification programmes.

\section{PROCESS FRAMEWORK DEVELOPMENT PHASES}

The development of the business process framework for the company is always a project. The general idea as state of the art of the project implementation phases is presented in [9]. However, practical cases on implementation have shown some 
additional rationale, which is good to be considered by any company that is going to use the SCOR for establishing a business process map. Illustratively, in [10] the SCOR is stated as an integrative guide, which provides a 'top-down' approach that requires the comparative analyses of post- and properformance indices as a basis of business process modification. The study discusses the limitations of current SCOR analysis and provides a mapping technique for gap mapping, problem prioritization, and business process modification in a supply chain setting. As such, it is one of the early empirical studies combining BPR and SCM disciplines. The research results can facilitate the implementation processes of multinational supply chain projects by identifying the gaps and linking them to the channel entities.

The current paper focuses on framework development phases from the perspective of the SCOR project core team work. The team normally should include a business process owner, business process developer and subject matter expertise. Additionally, a big value is coming from the super users of the processes, if such a role exists in an organisation, as they are the main persons who execute process daily.

\section{A. Understanding One's Own Company}

The first step in the journey of implementing the SCOR is to have a clear understanding of how it applies to one's own company. Since it is a model intended to be used in any sort of supply chains and is in fact used all over the world, it contains its own vocabulary and internal structure. However, usually supply chain terminology does not coincide with the vocabulary or mental structures one will find on one's own company.

On the other hand, not everything described in the SCOR is applicable to all companies, and not all that exists in all the companies is reflected in the SCOR. Thus, it is necessary to understand which parts of the model fit a company, and whether there are still some extra activities that should still be kept due to its added value for business.

This understanding and explanation of how the SCOR applies to one's own company is fundamental for many reasons, from which two may be highlighted:

- When "switching the model" from what you have to a SCOR perspective, many processes change their location in the process architecture, or even their structure. Premises and assumptions must be clearly formulated to assure that this is made in a consistent way through all the processes.

- Adopting the SCOR supposes a mind-set change in people, since it may suppose replacing a functional view with an end-to-end view of the processes. Changing a mind-set means involving different people in the company and helping them understand the new perspective being presented. This process is highly facilitated when the concepts are explained in a language that corresponds to the company's processes and culture.

In the project, this first step consists in defining on which levels processes will be drawn, explaining the meaning of every level, translating SCOR explanations into company's vocabulary, disseminating the knowledge about the SCOR among involved parties. Three main definitions have been invented for easier understanding of processes (see Fig.3):

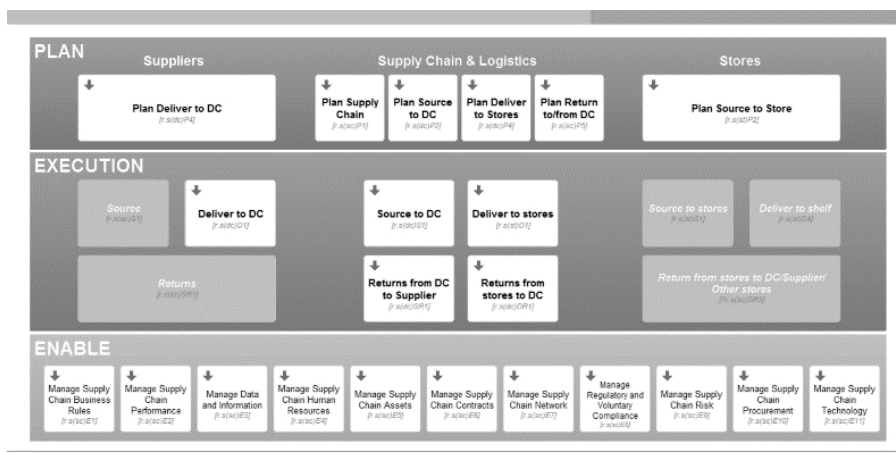

Fig. 3. Layout of company's business process map in the process management system.

1) Execution processes: all processes that involve scheduling the movement and moving goods and other physical items. Here are included Source, Deliver and Return processes.

2) Plan processes: all processes related to calculation and adjustment of volumes to guarantee that you have the required resources on time, so that the executions processes can run without interruption. The outputs of the Plan processes are a direct input for the Execution processes.

3) Enable processes: all processes that are not direct inputs into an Execution process but are pre-requisites for both Plan and Execution processes to happen. For example, one cannot plan the delivery of goods or buy them if they are not created in the system, but this does not mean that each time one creates the item in the system the Plan or Execution process is triggered.

Defining which SCOR processes are in or out of scope for the present phase of the project, "Make" process has been left out.

\section{B. Fitting Company's Processes into the SCOR}

The second step consists in fitting company's supply chain processes into the SCOR. Big part of company's supply chain process has already been designed, but in a functional view and at Level 5, i.e., activity-level. Each process consists basically in all activities executed by an area, mixing together components of Plan, Execution and Enable processes.

The effort of fitting into the SCOR consists of the following:

1) Drawing process architecture from SCOR Level 1 to Level 3, which has not existed within the current company's framework. It has been identified which of SCOR processes at Levels 1-3 are applicable to the company and connected together in the order they happen and make a company's end-to-end supply chain structure: Suppliers - Central Warehouse Local Warehouses - Customers.

2) Identifying into which Processes at Level 3 processes of Level 5 fit and distributing all the activities into some of the processes at Level 3. 
3) Building Level 4 that connects the already built Level 3 with Level 5 activities and processes that fit into them.

\section{Validating a Framework Hierarchy and Content}

Steps 1 and 2 consist of an effort carried mainly by the project main team, which includes business process owners and process developers. Only then, process subject matter experts, executives and super users are involved with the following objectives:

- to understand what SCOR is and how the new architecture looks like, since this is a process navigation tool for all process users in the company;

- to validate that processes are classified correctly into SCOR processes;

- $\quad$ to adjust Level 4 created by the core team, as well as creating the process diagrams that are still missing.

Two waves of workshops have been organised involving all process representatives. The first validation of the process map has been done from the functional perspective, inviting functional team representatives, mainly super users. Every function has been invited to give inputs to correct Level 4 and identify missing parts. The second wave of workshops has been organised to validate a process map from the process perspective, i.e., Source, Deliver and Return, involving representatives from all functional teams.

\section{D.Identifying Plan and Enable Processes}

When Execution processes are drawn, it is necessary to dig into Plan and Enable. For Plan each manager is requested to list the planning cycles they go through weekly, monthly or annually, and based on their input, the Plan processes are drawn into Level 4. Enable processes are drawn based on the existing processes of Level 5 already drawn previously and reallocated into the corresponding Enable process.

Both Plan and Enable processes require the strong mind-set change comparing with Execution processes, which are naturally easier for understanding. However, those processes are the most expensive for the company as they formalize the core strategic and tactical planning decisions of the company. For example, the Plan supply chain process is presented by a variety of plans existing in an organisation; however, those plans are not formalized as a process, and only few of them have descriptions.

Identifying and drawing Enable processes is the most challenging part, since there is a very poor understanding that these activities are processes, which are fundamental for the supply chain efficiency.

\section{LESSONS LEARNT AND CONCLUSION}

Creating a business process model is usually considered to be a creative process; however, in fact it requires a very strong discipline in the following consistent way of converting standard frameworks into practically applicable company's business process frameworks. Below are challenges and findings, which might be helpful for others considering to implement the SCOR framework.

\section{A. Challenges}

Maintaining consistency throughout the process architecture when talking about which parts of SCOR are applicable to a company and how. Interpretation and opinions have changed a lot in the first months and it is important to document the conclusions to avoid re-inventing the weal each time a process is reviewed.

Another challenge is about finding a vocabulary that would be easy for other employees to understand, but at the same time would still save the concepts contemplated in the SCOR.

However, the most important and difficult step is to make the employees to understand how their everyday job fits into the SCOR. One exercise that has proven very useful in this sense is the SCOR game, invented in a company by the SCOR ambassadors. It is a required training for all involved in the project. During the game process super users, managers and subject matter experts are first introduced to the SCOR methodology, then to the company's process map structure. Then they have a task to allocate the diagram with Level 4 process description to the corresponding process at Level 3. By doing this through the team work and discussions, they learn how to differ Enable processes from Plan processes, and how to use a new SCOR based end-to-end supply chain process map as a navigation tool through all supply chain processes.

\section{B. Good Practices}

It is fundamental to explain many times to employees what SCOR is and what the company's goals are. However, an important role here is to have definitions according to the company's vocabulary explaining the different concepts consistently whenever it is necessary to explain again what the SCOR is, as well as its different processes, levels, etc.

The business process framework is not an archive of the workflows and diagrams. It should serve both for strategic and tactical needs during development and optimization projects, as well as process automation initiatives. Therefore, involvement of the processes subject matter experts, as well as super users (for the concept of super user role in a company see [11]) is vital. Having people from each of the functional teams to validate the new process architecture and assist in fitting the company's processes into SCOR assisted both in validating the process by its executors and making process map closer to company's employees for supporting their needs related to process understanding.

Another important practice is to maintain a clear list of the assumptions considered when drawing the process architecture and reasoning, to maintain consistency in different diagrams and throughout time, when new discussions appear.

As a dissemination practice it is important to articulate and refer to the SCOR whenever it comes to discussion of operational process. For example, a product quality control process is always called in terms of SCOR as "Verify goods", explaining also its allocation in the SCOR map as Level 4 process being part of Level 3 Source to DC process. Thus, in the process diagrams, it is necessary to indicate in which level you are, to help people understand the levels. Whenever a flow moves from a process of Level 2 to another one of Level 3, this 
should also be clearly indicated so that people understand the connections between processes.

Training is another SCOR concept dissemination and educational activity. In the current case study, the trainings are first organised through educational sessions, which result in inhouse SCOR game where participants must solve a puzzle made by company's processes and fit it into the SCOR framework. In fact, the game replicates the way, how the company business process map is elaborated. The next intention is to make a computerised game to be used within a company, also as a part of new employee on a boarding program. One of such examples is described in [12] where SCOR simulation game is presented as a tool, which has broader learning objectives comparing the well-known supply chain education Beer Game.

\section{The Main Difficulties}

Even with a strong methodological support from APICS under affiliation of APICS membership, there still are a lot of difficulties any company should be ready to face when inventing a new business process framework.

Adopting the SCOR framework, mind-set change is needed, since processes that have previously been designed in a functional view are redesigned in an end-to-end process view.

Since all supply chain processes are affected, there are many workshops to cover all of them. In some cases, the same processes are re-drawn many times. For some cases, the process is first located under Execution processes, then moved to an Enable process, but ends up in Plan processes. During the learning path it is typical; however, it can be confusing for some people. Therefore, it is important to always have the right people in the room in order to avoid re-discussing processes.

Most of Plan and Enable processes have not been designed before and it has taken a lot of thinking to identify them on dayto-day operations and define to which level of detail they should be designed. The same challenge is related to the processes, which have already been automated in a company. Since people do not make any manual activity to support the process, they in some cases consider that process does not exist at all. However, through the discussions and process definitions by the SCOR those processes are clearly shown and stated as automated. This is a secondary benefit of the business process map standardisation because in the end the map shows the level of automation of end-to-end supply chain process.

\section{ACKNOWLEDGMENT}

This innovative journey of implementing the SCOR as an industry standard framework would not be possible without methodological support of APICS society. The team specially expresses their gratitude to the dedicated SCOR Ambassador Michael D'heur for his guidelines, directives and expertise leading the team to achieve the goal and keeping focus on the business value of the business process management related initiatives.

\section{REFERENCES}

[1] C. R. Moberg, and K. Vitasek, "Time to remodel" Q3, 2008. [Online]. Available: http://www.supplychainquarterly.com/print/scq200803scmmodel/ [Accessed: Aug. 18, 2018].

[2] D. M. Lambert, S. J. García-Dastugue, and K. L. Croxton, "An Evaluation of Process-Oriented Supply Chain Management Frameworks", Journal of Business Logistics, vol. 26, no. 1, 2005. https://doi.org/10.1002/j.2158-1592.2005.tb00193.x

[3] APICS home page [Online] Available: https://www.apics.org [Aug. 09, 2018]

[4] APICS, "Supply Chain Operations Reference Model SCOR V12.0”, 2017.

[5] H. Zhou, W. C. Benton Jr., D. A. Schilling, and G. W. Milligan, "Supply Chain Integration and the SCOR Model”, Journal of Business Logistics, vol. 32, no. 4, pp. 332-344, 2011. https://doi.org/10.1111/j.0000-0000.2011.01029.x

[6] D. Jothimani, and S. P. Sarmah, "Supply chain performance measurement for third party logistics", Benchmarking: An International Journal, vol. 21, no. 6, pp. 944-963, 2014. https://doi.org/10.1108/BIJ-09-2012-0064

[7] D. M. Lambert, M. C. Cooper, and J. D. Pagh, "Supply Chain Management: Implementation Issues and Research Opportunities", The International Journal of Logistics Management, vol. 9, no. 2, pp. 1-20, 1998. https://doi.org/10.1108/09574099810805807

[8] APQC home page [Online] Available: https://www.apqc.org [Aug. 09, 2018]

[9] P. Bolstorff, and R. Rosenbaum, "Supply Chain Excellence: A Handbook for Dramatic Improvement Using the SCOR Model", Amacom, 2003.

[10] W. Y. C. Wang, H. K. Chan, and D. J. Pauleen, "Aligning Business Process Reengineering in Implementing Global Supply Chain Systems by the SCOR Model", International Journal of Production Research, vol. 48, no. 19, 2009. https://doi.org/10.1080/00207540903168090

[11] L. M. Rizoto-Vidala-Pesoa, and O. Kuznecova, "The Role of the Super User in Achieving Business Process Management Maturity", Information Technology and Management Science, vol. 20, no. 1, pp. 74-78, 2018. https://doi.org/10.1515/itms-2017-0013

[12] G. S. Webb, S. P. Thomas, and S. Liao-Troth, "Teaching Supply Chain Management Complexities: A SCOR Model Based Classroom Simulation", Decision Sciences Journal of Innovative Education, vol. 12, no. 3, 2014. https://doi.org/10.1111/dsji.12038

[13] APQC, "Process Classification Framework V6.11", 2015.

Andrejs Girjatovičs is an experienced practitioner in FMCG industry. He has more than a 10-year experience in retail with expertise in store management, supply management, forecasting and replenishment process automation. As a Business Process Owner Andrejs has been involved in a variety of the process improvement projects, including applying of the SCOR model for a retail company as part of process unification project. Since 2018, Andrejs has a leading role in a supply chain process harmonization project as a Supply Chain Business Analyst and has been continuing his work on supplementing company's business process framework with standardised supply chain performance metrics. His professional interests are related to innovation, process automation, optimization, data-driven decision-making support tools development, as well as big data.

E-mail: Andrejs.Girjatovics@rimibaltic.com

Laila Māra Rizoto-Vidala-Pesoa received a Master's degree in 2015 in Management Science from the University of Latvia. As a Supply Chain Process Owner, Laila has worked in the implementation of the SCOR model in supply chain processes for a retail company in the Baltic States. At present, Laila works in the Business Process Excellence Global Team at Cabot Corporation, participating in the upgrade of the company's ERP system and coordinating the review of global standard documentation. Her professional interests are related to business process management expertise.

E-mail: lailamrvp@gmail.com

Oksana Kuzṇecova obtained a Dr. sc. ing. degree in 2015. She has more than 10 years of academic experience as a Lecturer and Researcher at the Department of Modelling and Simulation of Riga Technical University, Latvia. Since 2015, Oksana has been working at RIMI Baltic as a Business Lead in supply chain process automation and harmonization projects. Now she is holding the position of Supply Chain Development Manager in SC Development and Optimization team. Her professional interests are supply chain development and optimization, as well as operational excellence.

E-mail: Oksana.Kuznecova@rimibaltic.com 